\title{
Grain Yield Differences of Soybean Cultivars Due to Solar Radiation Interception
}

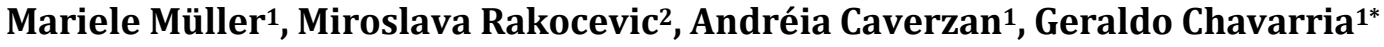 \\ ${ }^{1}$ Faculty of Agronomy and Veterinary Medicine, Agronomy Post-Graduate Program, University of Passo Fundo, Passo Fundo, \\ Brazil \\ ${ }^{2}$ Embrapa Agriculture Informatics, Campinas, Brazil \\ Email: *geraldochavarria@upf.br
}

How to cite this paper: Müller, M., Rakocevic, M., Caverzan, A. and Chavarria, G. (2017) Grain Yield Differences of Soybean Cultivars Due to Solar Radiation Interception. American Journal of Plant Sciences, 8, 2795-2810.

https://doi.org/10.4236/ajps.2017.811189

Received: September 2, 2017

Accepted: October 23, 2017

Published: October 26, 2017

Copyright (C) 2017 by authors and Scientific Research Publishing Inc. This work is licensed under the Creative Commons Attribution International License (CC BY 4.0).

http://creativecommons.org/licenses/by/4.0/

\begin{abstract}
Soybean [Glycine $\max ($ L.) Merr.] growth rate and grain yield are modified by the interception and solar radiation use efficiency. Thus, it is desirable that the most of plant photosynthetic structures intercepting solar radiation in order to have increment in carbon fixation and reflection on growth and yield. The goal of this study was to assess if soybean cultivars differ in grain yield in relation to solar radiation interception. Four soybean cultivars were evaluated at stages V6, V9, R2, R4, R6 and R8. To determine the photosynthetically active radiation interception by the canopy, the plants were divided into two parts (upper and lower strata). For grain yield components, the plants were divided into three parts (upper, middle and lower thirds). Of the photosynthetically active radiation intercepted by the vegetative canopy at the reproductive stages, the maximum observed intercept was $5.2 \%$ in the lower stratum of the plants. The number of infertile nodes increased in the lower third of plants due to low interception of solar radiation in this plant region. Thus, the soybean cultivars more efficient in intercepting photosynthetically active radiation inside the vegetative canopy showed higher grain yields.
\end{abstract}

\section{Keywords}

Glycine Max, Leaf Area Index, Efficiency of Solar Radiation Interception, Extinction Coefficient, Solar Radiation Use Efficiency

\section{Introduction}

Plant growth depends on carbon assimilation, which is directly related to intercepted photosynthetically active radiation (IPAR). Part of photosynthetically active radiation (PAR) is absorbed and used in photosynthesis, and the rest is lost 
to the environment [1]. Plant growth rates can be obtained by estimating solar radiation use efficiency ( $R U E$ ), which is defined by the ratio between biomass increase and radiation intercepted by the plant canopy [2] [3].

Radiation interception efficiency (RIE), the fraction of light intercepted by the plants, can be high or low [4], and depends on the leaf area index and morphological characteristics [5]. The shading decreases total soluble sugar concentration in soybean leaves, causing reduced numbers of pods; reduction of $42.5 \%$ in the number of pods is observed for plants shaded during the cycle, while the increase of light availability brought about increases of $59.5 \%$ in the number of pods [6].

The determination of RIE must be evaluated not only for the plant-atmosphere edge, but also across plant canopy in a stratified manner. However, the IPAR of the whole plant has major importance for grain yield quantification. Most of the sugars synthesized by plants are transported short distances by the phloem [7]. In this way, the leaves supply the drains through direct vascular connections [8], so the filling of pods in a node occurs mainly by photoassimilates produced by the leaves into which pods are inserted. Seed weights were reduced by removing $66 \%$ and $99 \%$ leaves, by the low production and translocation of photoassimilates during grain filling [9]. Therefore, greater shading and defoliation levels for crops at reproductive stages causes, reduced grain filling.

The soybean plant architecture varies with genotype, presenting a wide variety of forms, but a lack of knowledge on how much architectural features influence IPAR. The IPAR varies with leaf area index (LAI) and light extinction coefficient (k) [2] [10] [11]. The soybean showed $k$ values of 0.52 and 0.93 before and after flowering, respectively, due to increased LAI with the growth of the plants [12]. The higher the LAI, the greater the IPAR, but from a certain increase in the leaf area the shading of the lower leaves of the plant can be intensified [13]. Thereby, there might be an energy imbalance in plants since the shaded structures spend energy in respiration, without producing through photosynthesis. Leaf senescence in the canopy lower part is accelerated due to a decrease in the proportion of red and far red light, signaling that light conditions would not satisfy the primary metabolism demands [14].

The knowledge about the solar radiation interception by strata of plant canopies can help to understand how this factor affects soybean growth and grain yield. Our hypothesis was that soybean plants with an architecture that allows more solar radiation interception inside of canopy would show better productive performances. Thus, the aim of this work was to evaluate if soybean cultivars differ in grain yield in relation to solar radiation interception.

\section{Materials and Methods}

\subsection{Study Subject and Experimental Design}

Soybean cultivars with different agronomic traits were used. Seeds had germination percentages above $90 \%$ and vigour superior to $85 \%$. For each cultivar, we 
followed the breeder company recommendations regarding the number of plants $\cdot \mathrm{ha}^{-1}$ and sowing time.

The treatments consisted of four cultivars BMX Ativa RR, BMX Potência RR, NA 5909 RG and 95R51. Cultivars BMX Potência RR, NA 5909 RG, and 95R51 have indeterminate growth habit, while BMX Ativa RR has the determinate habit. Maturation groups were different among cultivars, being 5.1, 5.6, 5.9, and 6.7 for cultivars 95R51, BMX Ativa RR, NA 5909 RG and BMX Potência RR, respectively.

The experiment was conducted in a randomized complete block design with five replicates, totaling 20 experimental units. Plots consisted of seven $10-\mathrm{m}$ sowing rows spaced $0.45 \mathrm{~m}$ apart. Two outer rows were left as borders in addition to the outer $0.5 \mathrm{~m}$ at the end of each plot. Destructive measurements were carried out on plants within a 4-m row segment, leaving 5-m for final yield determination after harvesting.

\subsection{Procedures}

The study was conducted in the city of Passo Fundo, RS (Brazil) $\left(28^{\circ} 12^{\prime} \mathrm{S}\right.$ and $52^{\circ} 23^{\prime} \mathrm{W}$, altitude $\left.667-\mathrm{m}\right)$. The climate is of the humid subtropical type [15]. The soil is classified as a humic dystrophic red latosol [16].

Sowing was north-south oriented, being carried out in a no-tillage system, over wheat crop remains. At sowing, fertilization consisted of $6 \mathrm{~kg} \cdot \mathrm{ha}^{-1} \mathrm{~N}, 60$ $\mathrm{kg} \cdot \mathrm{ha}^{-1} \mathrm{P}_{2} \mathrm{O}_{5}$, and $60 \mathrm{~kg} \cdot \mathrm{ha}^{-1} \mathrm{~K}_{2} \mathrm{O}$. Seeds were inoculated with Bradyrhizobium japonicum and treated with insecticides and fungicides according to crop recommendations [17].

The adopted seeding densities were 15.75 plants $\cdot \mathrm{m}^{-1}$ for BMX Ativa RR, 15.30 plants $\cdot \mathrm{m}^{-1}$ for NA $5909 \mathrm{RG}, 17.10$ plants $\cdot \mathrm{m}^{-1}$ for $95 \mathrm{R} 51$, and 12.60 plants $\cdot \mathrm{m}^{-1}$ for BMX Potência RR. Phytosanitary management was preventive so that there was no interference with plant growth, and mainly regarding the architectural traits of the cultivars [17].

The evaluations took place at the following phenological stages: V6 (fifth fully expanded trifoliolate leaf), V9 (eighth fully expanded trifoliolate leaf), R2 (full bloom), R4 (fully developed pod), R6 (full grain) and R8 (physiological maturity) $[18]$.

\subsection{Solar Radiation Interception Efficiency}

The photosynthetically active radiation (PAR, $\mu \mathrm{mol} \cdot \mathrm{m}^{-2} \cdot \mathrm{s}^{-1}$ ) was measured using a ceptometer (AccuPAR LP-80; DECAGON Devices) at V6, V9, R2, and R4 stages. The readings were made hourly from sunrise to sunset, always on the same plants, totaling 60 measurements per hour. The $k$ and RIE were measured at $11 \mathrm{~h}, 12 \mathrm{~h}$, and $13 \mathrm{~h}$.

Plant dry mass (DM) was determined using 10 plants per plot, so totaling 50 plants per cultivar at all stages (V6, V9, R2, R4, and R6). The plants were collected following a sequence along the row length, being manually cut close to the 
soil and taken to an oven for drying at $60^{\circ} \mathrm{C}$ until reaching a constant weight. After drying, each plant was weighed $\left(\mathrm{g} \cdot \mathrm{pl}^{-1}\right)$.

Leaf area (LA) was measured by a destructive method using the leaf area integrator (LI-3100C, LI-COR BIOCIENCE Inc.). Ten plants were collected following a sequence along the row length at V6, V9, R2, and R4 stages. Leaf area index (LAI) was estimated by the ratio between the total leaf area and the projected area of the soil (PA) $\left(\mathrm{m}^{2} \cdot \mathrm{m}^{-2}\right)$ (Equation (1)):

$$
\mathrm{LAI}=\mathrm{LA} / \mathrm{PA}
$$

The interception of photosynthetically active radiation (IPAR) by canopy total was estimated from measurements of incident solar radiation (ISR) and transmitted fraction (TF) to the soil surface (Equation (2)):

$$
\mathrm{IPAR}=\mathrm{ISR}-\mathrm{TF}
$$

The IPAR in the upper stratum (US) was determined from incident solar radiation (ISR) ( $5 \mathrm{~cm}$ above the canopy) less the IPAR measured at half canopy height $(\mathrm{HCH})$ (Equation (3)):

$$
\mathrm{US}=\mathrm{ISR}-\mathrm{HCH}
$$

The IPAR in the lower stratum (LS) was determined from $\mathrm{HCH}$ less TF (Equation (4)):

$$
\mathrm{LS}=\mathrm{HCH}-\mathrm{TF}
$$

The efficiency of solar radiation interception (RIE) was determined from the quotient between the intercepted photosynthetically active radiation (IPAR) and the total ISR on the vegetative canopy (Equation (5)):

$$
\mathrm{RIE}=\mathrm{IPAR} / \mathrm{ISR}
$$

The canopy extinction coefficient $(k)$ was determined from the means of solar radiation interception efficiency and leaf area indexes (LAI), estimated by the theory proposed by [19], based on the assumptions of the Beer's Law [20] (Equation (6)):

$$
\operatorname{Ln}(1-\mathrm{RIE})=k^{*} \mathrm{LAI}
$$

Radiation use efficiency (RUE), expressed in $\mathrm{g} \cdot \mathrm{MJ}^{-1}$, was estimated by regression analysis between plant-accumulated DM $\left(\mathrm{g} \cdot \mathrm{m}^{-2}\right)$ and IPAR sum $\left(\mathrm{MJ} \cdot \mathrm{m}^{-2}\right)$ during the crop cycle, according to [21]. In this study the IPAR used, was determined by the incident global radiation and transformed in PAR using the conversion factor 0.45 [22]. In addition, the interception efficiency of the plants of each cultivar was considered, because the canopy did not intercept all PAR. In this sense, the RUE is $\mathrm{g} \cdot \mathrm{MJ}^{-1}$ of IPAR (Equation (7)):

$$
\mathrm{RUE}=\mathrm{DM} / \mathrm{IPAR}
$$

For RUE calculations, data had to be transformed from $\mu \mathrm{mol} \cdot \mathrm{s}^{-1} \cdot \mathrm{m}^{-2}$ to $\mathrm{MJ} \cdot \mathrm{m}^{-2} \cdot \mathrm{day}^{-1}$, using a single conversion value for each environment [23], where $t$ 
is time between PAR readings (3600 seconds) and 4.57 is the conversion value (Equation (8)):

$$
\begin{aligned}
& \text { PAR } \\
& =\sum \operatorname{day}\left(\operatorname{PAR}\left(\mu \mathrm{mol} \cdot \mathrm{s}^{-1} \cdot \mathrm{m}^{-2}\right) * t(s)\right) /\left(4.57\left(\mathrm{MJ} \cdot \mathrm{m}^{-2} \cdot \text { day }^{-1}\right)\right) / 1000000
\end{aligned}
$$

\subsection{Fruiting}

Effective fruiting was determined by counting reproductive structures (flowers and pods) at $\mathrm{R} 2, \mathrm{R} 4$, and $\mathrm{R} 8$ reproductive stages for the lower, the middle, and the upper thirds of the plant canopy. Plant height was measured and then divided into three parts (thirds), including the branches.

\subsection{Grain Yield Components}

At physiological maturity, 10 plants were collected following the sequence of the row in each experimental unit to evaluating the yield components by plant thirds. The number of fertile nodes (FN), infertile nodes (IN), grains number (GN), grain mass (GM), thousand-grain mass (TGM), and grain yield (GY) was determined. For GM estimation, moisture was corrected to $13 \%$ [17]. Finally, grain yield per hectare $\left(\mathrm{kg} \cdot \mathrm{ha}^{-1}\right)$ of each plant third was defined.

In addition to GY of each plant third, an area of $9 \mathrm{~m}^{2}$ was harvested using a WINTERSTEIGER Classic plot harvester. The samples were weighed and corrected for $13 \%$ moisture, and the GY $\left(\mathrm{kg}_{\mathrm{h}} \mathrm{ha}^{-1}\right)$ and TGM (g) were definedfor whole plants.

\subsection{Statistical Analysis}

Data were subjected to analysis of variance (ANOVA), and means were compared by Tukey's test at probability lower than 0.05 of error. Moreover, the Pearson correlation was calculated among variables lower than 0.05 error probability.

\section{Results}

\subsection{Solar Radiation Interception Efficiency and Plant Growth}

Given the short stature of plants at V6 stage (maximum height of $18.3 \mathrm{~cm}$ ), solar radiation availability was evaluated at above canopy and at ground level, to give the total amount intercepted by the canopy (Figure 1). During vegetative stage, there were no differences in IPAR measurements, however, during the reproductive stage, the IPAR of cultivars differed significantly.

As plants grew, the amount of IPAR at the lower stratum of canopy decreased (Figure 1). Regarding the lower stratum, all cultivars reached a maximum IPAR, nearly $18 \%$ total interception, at V9 stage. Conversely, at R2 stage, these values were $2.7 \%, 1.4 \%, 4.7 \%$, and 1.1\% for BMX Ativa RR, NA 5909 RG, 95R51, and BMX Potência RR, respectively; while in R4 stage, with the decrease of LAI, there were a slight increase in interception, being $4.4 \%, 1.0 \%, 5.1 \%, 1.5 \%$, respectively. 

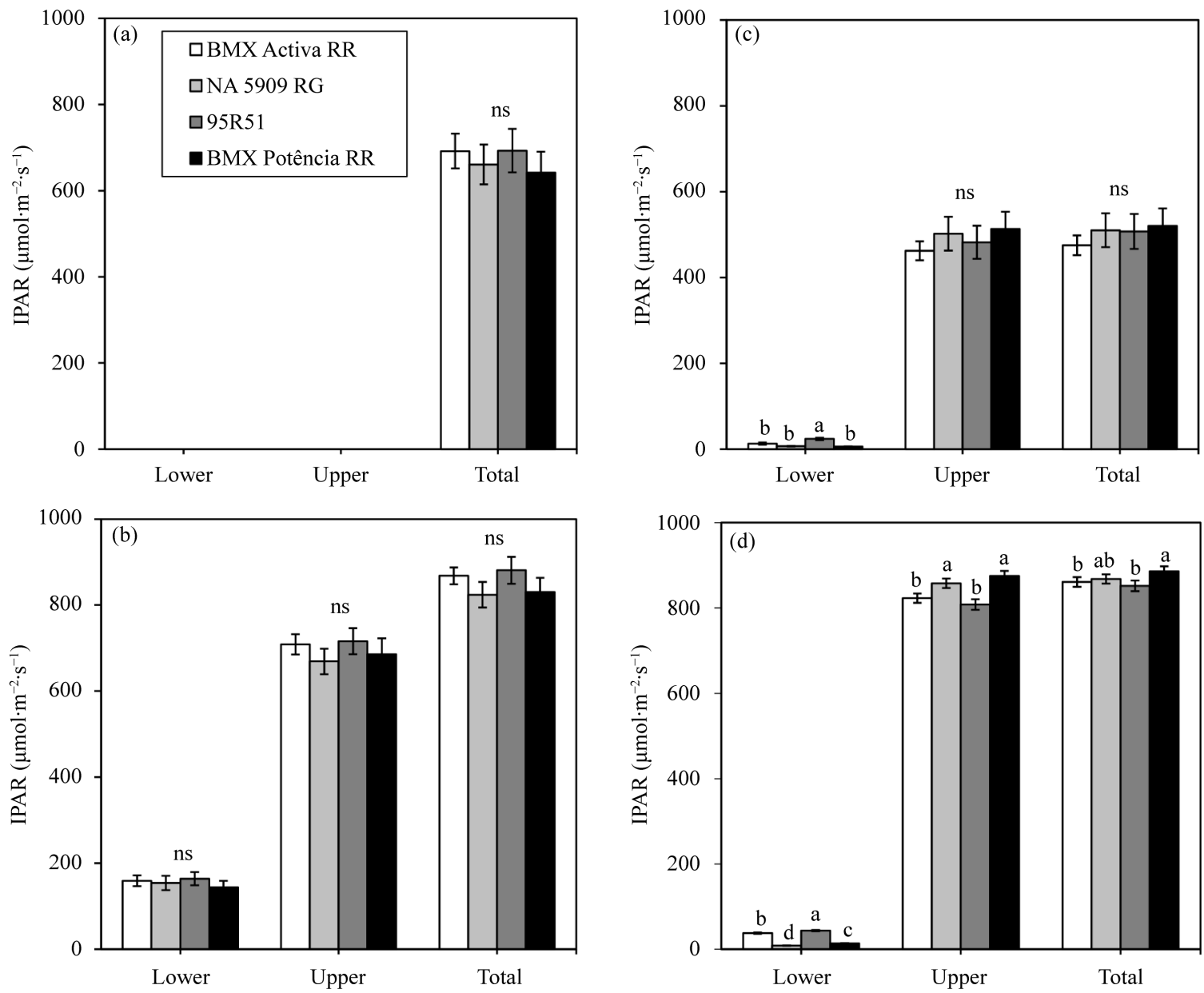

Figure 1. Interception of photosynthetically active radiation (IPAR) by soybean cultivars with different architectural characteristics during the day, values in the upper and lower stratum, and in the total plant canopy. Phenological stages: (a) V6, (b) V9, (c) R2, and (d) R4. Means followed by the same letter in the columns do not differ from each other at 0.05 probability by the Tukey's test by phenological stage. Vertical bars represent the standard error. ns: non-significant.

The highest LAI values were observed at $\mathrm{R} 2$ stage, with variations among cultivars at 5.2, 6.9, 4.2, and 6.2 for BMX Ativa RR, NA 5909 RG, 95R51, and BMX Potência RR, respectively (Figure 2). There was a leaf fall at R4 stage that resulted in a LAI decrease of 1.1, 2.1, 0.4, and 1.5 for cultivars BMX Ativa RR, NA 5909 RG, 95R51, and BMX Potência RR, respectively. The highest $k$ values were observed at V6 stage when plants showed high RIE, even under low LAI values. The same trend of $k$ values continued until R2 stage in all cultivars, with the highest values at V6 stage, decreasing at V9 stage and increasing at R2 stage. Nonetheless, there was a decrease for cultivar 95R51 only at R4 stage, remaining virtually constant for BMX Ativa RR, while the other cultivars showed an increasing trend (Figure 2).

The lowest value of RIE (0.79) was observed for cultivar BMX Potência RR at V6 stage, whereas the highest value was 0.99 for all the cultivars at R2 stage (Figure 2). There was an alteration in RIE before and after flowering, averaging 

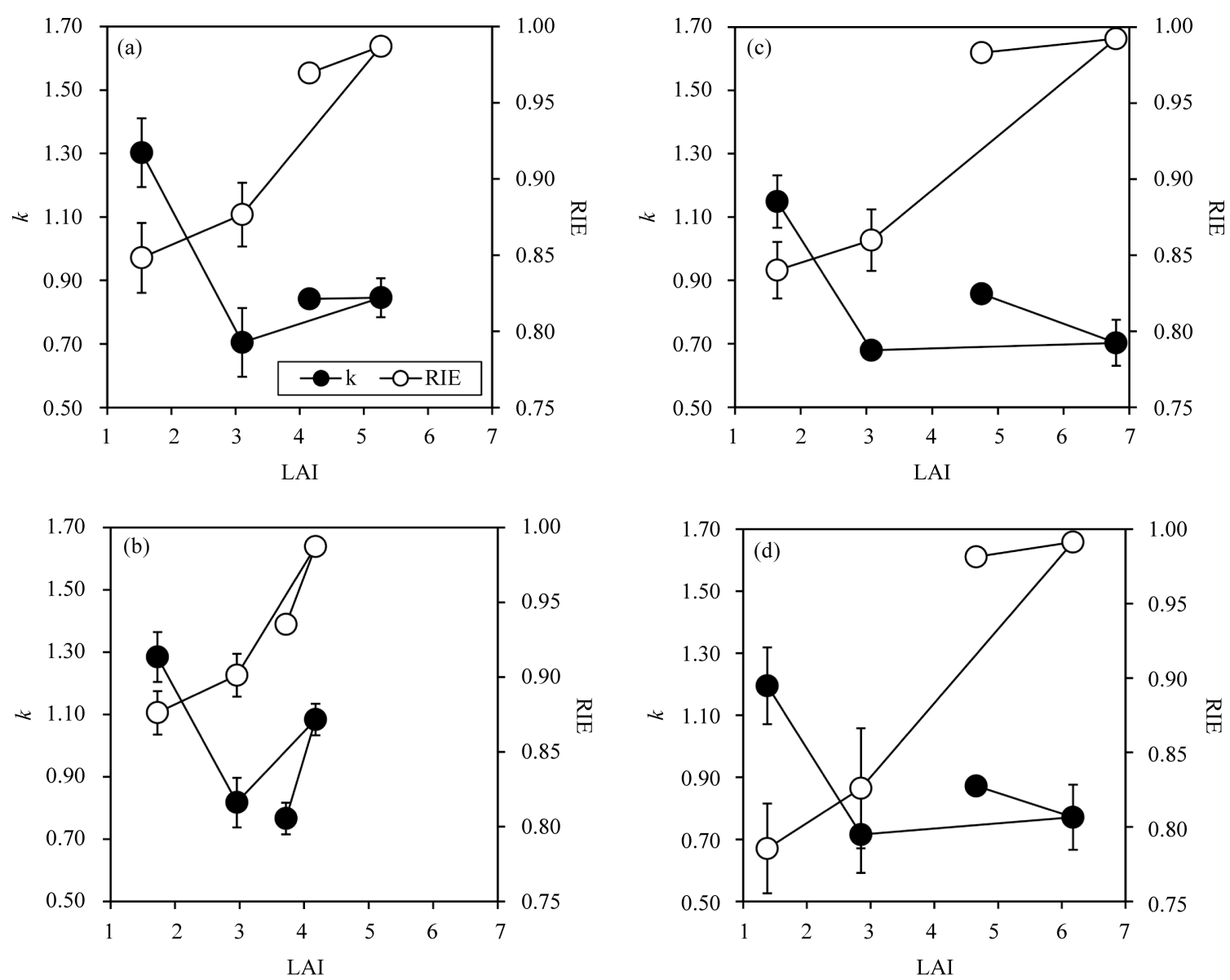

Figure 2. Light extinction coefficient as a function of leaf area index (LAI) and radiation interception efficiency (RIE) along the phenological stages V6, V9, R2, and R4. (a) BMX Ativa RR, (b) 95R51, (c) NA 5909 RG, and (d) BMX Potência RR. $k$. Light extinction coefficient (primary y-axis). RIE: radiation interception efficiency (secondary $\mathrm{y}$-axis). LAI: leaf area index (x-axis). Vertical bars represent the standard error.

from $0.86,0.85,0.89$, and 0.81 to $0.98,0.98,0.96$, and 0.98 for BMX Ativa RR, NA 5909 RG, 95R51, and BMX Potência RR, respectively.

The amount of PAR accumulated during the growing season was dependent on cycle duration and RIE. The total PAR for BMX Ativa RR, NA 5909 RG, 95R51, and BMX Potência RR were 825, 819, 775, and $878 \mathrm{MJ} \cdot \mathrm{m}^{-2}$, respectively, (Figure 3). BMX Potência RR has the longest cycle and achieved the highest accumulation value of PAR.

RUE showed1.6, 1.8, 1.8, and $1.5 \mathrm{~g} \cdot \mathrm{MJ}^{-1}$ of IPAR for cultivars BMX Ativa RR, NA 5909 RG, 95R51, and BMX Potência RR, respectively (Figure 3). Although BMX Potência RR had intercepted more PAR than the other cultivars, it had the lowest efficiency in converting solar radiation to DM. To reach a shoot DM of $100 \mathrm{~g} \cdot \mathrm{m}^{-2}$, the studied cultivars required 275 (BMX Ativa RR), 268 (NA 5909 RG), 319 (95R51), and 255 (BMX Potência RR) MJ.m ${ }^{-2}$ IPAR. These results highlight the highest RUE of BMX Potência RR at the beginning of vegetative development. Conversely, to achieve a shoot DM production of $1000 \mathrm{~g} \cdot \mathrm{m}^{-2}$, cultivars required 734 (BMX Ativa RR), 673 (NA 5909 RG), 679 (95R51), and 

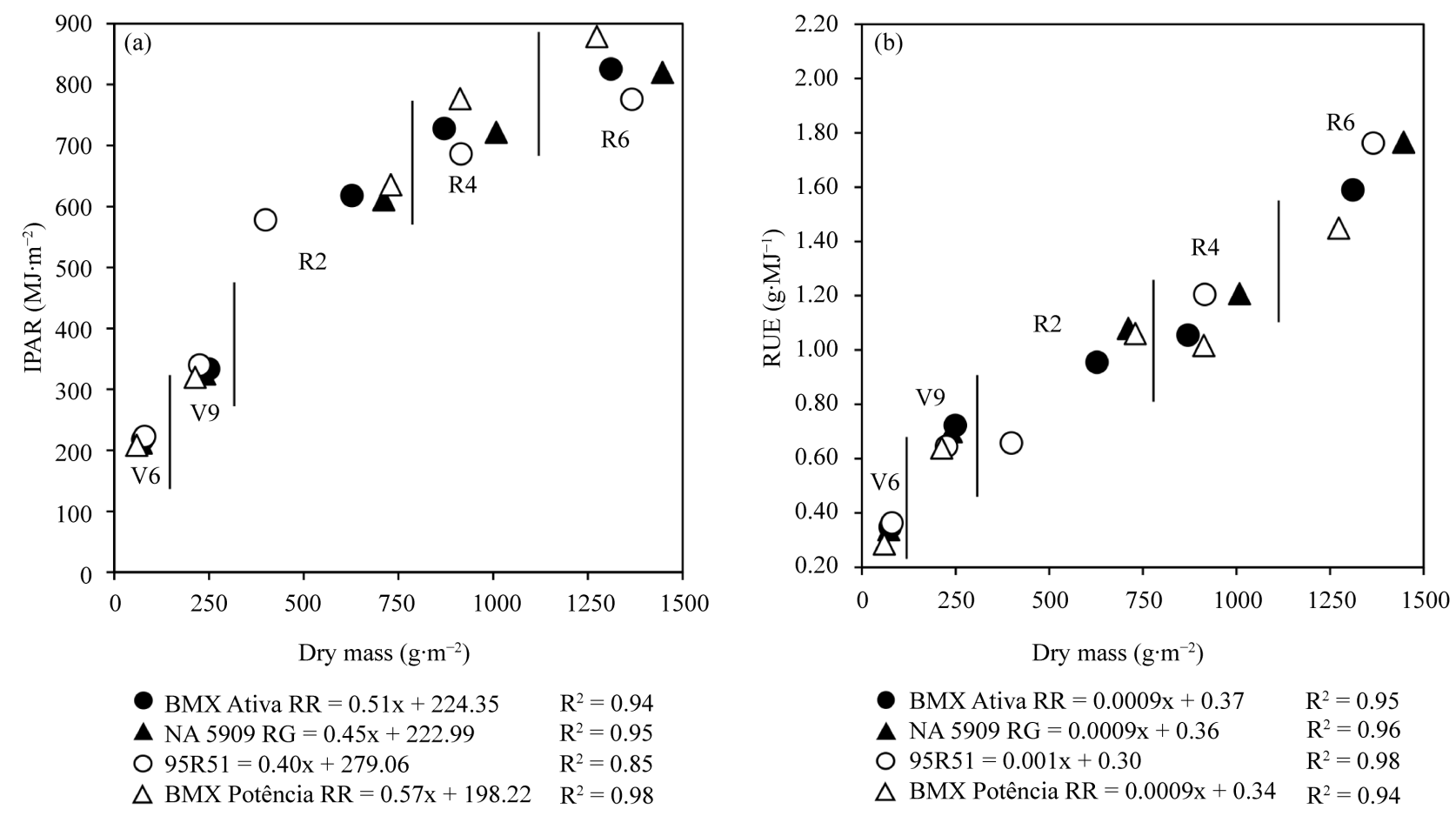

Figure 3. Intercepted photosynthetically active radiation (IPAR) and radiation use efficiency (RUE) relationship with dry mass produced by soybean cultivars with different architectural characteristics at V6, V9, R2, R4, and R6 stages. (a) IPAR: Intercepted photosynthetically active radiation (y-axis). (b) RUE: radiation use efficiency (y-axis). DM: dry mass (x-axis).

$768 \mathrm{MJ} \cdot \mathrm{m}^{-2}$ of IPAR. Therefore, RUE of BMX Potência RR was reduced during the reproductive stage when compared to the other cultivars.

\subsection{Dynamics of Pod Production}

At R2 stage and full bloom stage, BMX Potência RR was superior in the number of reproductive structures when compared to the others (Figure 4). Nevertheless, this result had no effect on fruiting. Both BMX Ativa RR and 95R51 cultivars had the smallest number of reproductive structures at R2 stage, with the highest percentages of effective fruiting in the lower third of the canopy. Evaluating fruiting effectiveness, BMX Potência RR cultivar showed lower reproductive structures in the medium third, while BMX Ativa RR was the most productive in the upper third, without differing from NA 5909 RG. The maximum effectiveness of fruiting in the lower third was $22 \%$ for $95 \mathrm{R} 51$ cultivar, while for BMX Ativa RR this was achieved in the medium (81\%) and in the upper (85\%) thirds.

\subsection{Grain Yield Components}

Among the cultivars, 95R51 reached the highest productivity in the lower third due the least number of infertile nodes per plant (IN) (Table 1). The ratio between IN and fertile nodes per plant (FN) in the lower third was nearly 4 for BMX Ativa RR, 12 for NA 5909 RG, 1 for 95R51, and 2 for BMX Potência RR. Therefore, 95R51 had the highest grains number per plant (GN) and, consequently, 

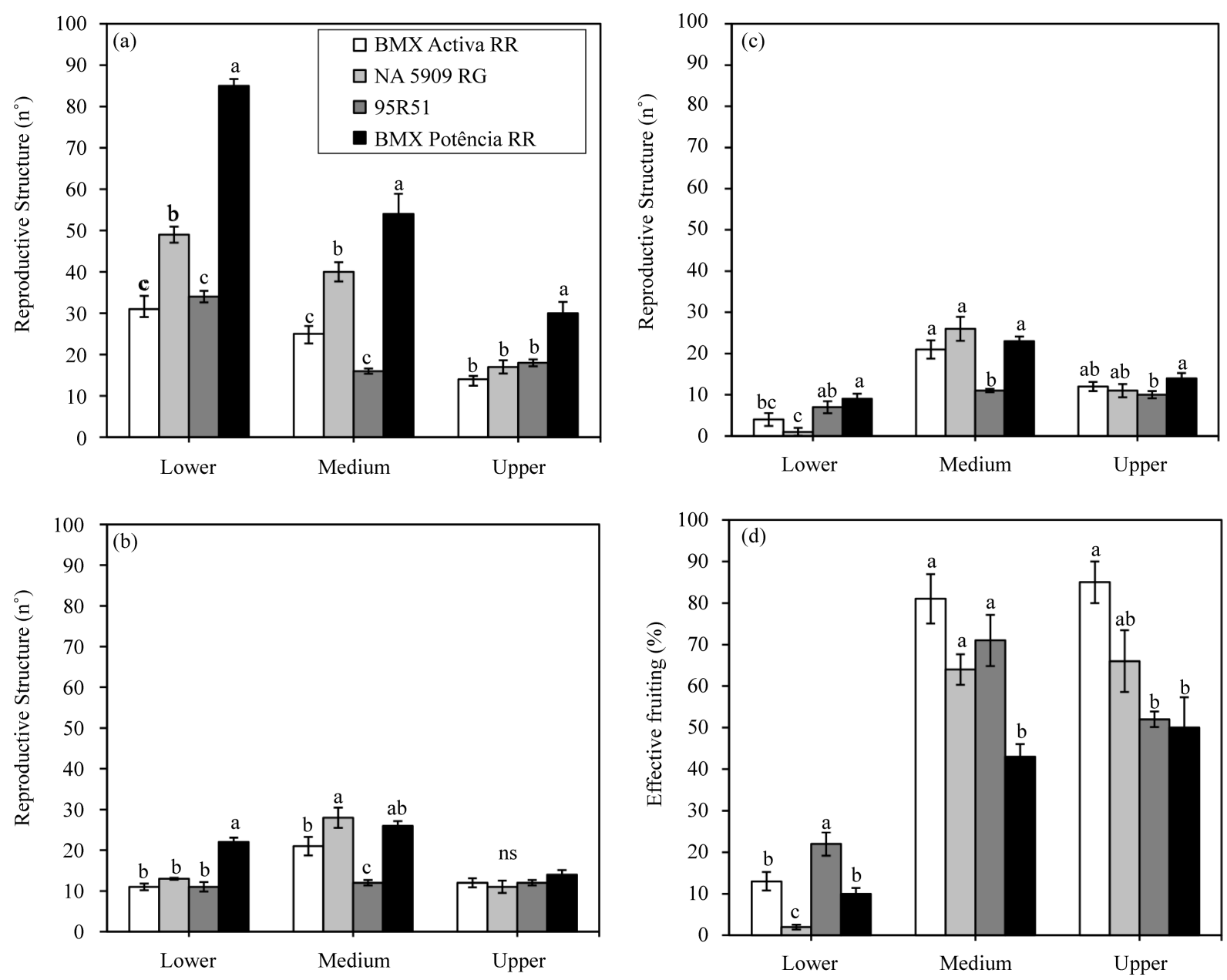

Figure 4. Number of reproductive structures of soybean cultivars with different architectural characteristics per plant third. (a) Phenological stages: R2, (b) R4, (c) R8, and (d) effective fruiting. Means followed by the same letter in the columns (per third) do not differ from each other at 0.05 probability by the Tukey's test. Vertical bars represent the standard error. ns: non-significant.

the highest GM per plant, with a yield about $500 \mathrm{~kg} \cdot \mathrm{ha}^{-1}$ higher than that of BMX Potência RR in the lower third. NA 5909 RG, which showed high IN to FN ratio in the lower third, showed the lowest GM per plant, yielding about 1200 $\mathrm{kg} \cdot \mathrm{ha}^{-1}$ less than $95 \mathrm{R} 51$.

Despite the differences in yield components in the middle third, the final yield showed no difference among cultivars for this plant region (Table 1). In the upper third, BMX Potência RR and NA 5909 RG showed superior performances in FN and GN, given their higher number of nodes and the lack of variation in IN among cultivars. Conversely, there was no difference for GM per plant among the cultivars, which was due to a lower thousand grain mass (TGM) for BMX Potência RR and NA 5909 RG, which may have influenced the final grain yield (GY). Evaluations of whole plants, through mechanized harvesting, showed that 95R51 obtained the highest GY, while BMX Potência RR was the least productive (Table 2). 
Table 1. Yield components per canopy third for soybean cultivars with different architectural characteristics.

\begin{tabular}{|c|c|c|c|c|c|c|}
\hline Cultivars & $\mathrm{FN}\left(\mathrm{n}^{\circ}\right)$ & $\operatorname{IN}\left(n^{\circ}\right)$ & $\mathrm{GN}\left(\mathrm{n}^{\circ}\right)$ & GM (g) & TGM (g) & GY $\left(\mathrm{kg} \cdot \mathrm{ha}^{-1}\right)$ \\
\hline & \multicolumn{6}{|c|}{ Lower third of the plants } \\
\hline BMX Ativa RR & $2.78 \mathrm{~b}$ & $8.82 \mathrm{~b}$ & $6.22 c$ & $1.23 \mathrm{c}$ & $197.89 \mathrm{~ns}$ & $467.73 \mathrm{c}$ \\
\hline NA 5909 RG & $1.14 \mathrm{c}$ & $13.82 \mathrm{a}$ & $3.34 \mathrm{~d}$ & $0.53 \mathrm{~d}$ & 162.69 & $203.86 \mathrm{~d}$ \\
\hline $95 \mathrm{R} 51$ & $5.16 \mathrm{a}$ & $5.40 \mathrm{c}$ & $20.06 \mathrm{a}$ & $3.71 \mathrm{a}$ & 185.07 & $1412.41 \mathrm{a}$ \\
\hline BMX Potência RR & $4.68 \mathrm{a}$ & $14.30 \mathrm{a}$ & $18.08 \mathrm{~b}$ & $2.61 \mathrm{~b}$ & 144.40 & $992.54 \mathrm{~b}$ \\
\hline \multirow[t]{2}{*}{ CV (\%) } & 15.07 & 10.56 & 7.78 & 16.08 & 19.31 & 16.12 \\
\hline & \multicolumn{6}{|c|}{ Medium third of the plants } \\
\hline BMX Ativa RR & $7.46 \mathrm{~b}$ & $0.22 \mathrm{c}$ & $44.52 \mathrm{~b}$ & $8.59 \mathrm{ab}$ & $192.68 \mathrm{a}$ & $3007.85 \mathrm{~ns}$ \\
\hline NA 5909 RG & $12.52 \mathrm{a}$ & $1.60 \mathrm{a}$ & $53.54 \mathrm{a}$ & $9.02 \mathrm{a}$ & $168.98 \mathrm{ab}$ & 3067.39 \\
\hline $95 \mathrm{R} 51$ & $5.30 \mathrm{~b}$ & $0.64 \mathrm{~b}$ & $31.22 \mathrm{c}$ & $6.38 \mathrm{~b}$ & $203.86 \mathrm{a}$ & 2427.68 \\
\hline BMX Potência RR & $11.54 \mathrm{a}$ & $0.70 \mathrm{~b}$ & $57.66 \mathrm{a}$ & $8.55 \mathrm{ab}$ & $148.56 \mathrm{~b}$ & 2393.91 \\
\hline \multirow[t]{2}{*}{ CV (\%) } & 13.15 & 28.23 & 9.86 & 14.65 & 11.66 & 15.32 \\
\hline & \multicolumn{6}{|c|}{ Upper third of the plants } \\
\hline BMX Ativa RR & $4.42 \mathrm{~b}$ & $0.04 \mathrm{~ns}$ & $27.42 \mathrm{ab}$ & $5.18 \mathrm{~ns}$ & $189.88 \mathrm{a}$ & $1812.31 \mathrm{a}$ \\
\hline NA 5909 RG & $5.98 \mathrm{a}$ & 0.04 & $31.86 \mathrm{a}$ & 5.33 & $168.54 \mathrm{ab}$ & $1815.48 \mathrm{a}$ \\
\hline $95 \mathrm{R} 51$ & $4.10 \mathrm{~b}$ & 0.06 & $21.24 \mathrm{~b}$ & 4.25 & $202.60 \mathrm{a}$ & $1617.85 \mathrm{ab}$ \\
\hline BMX Potência RR & $6.04 \mathrm{a}$ & 0.1 & $32.68 \mathrm{a}$ & 4.44 & $134.94 \mathrm{~b}$ & $1244.55 \mathrm{~b}$ \\
\hline CV (\%) & 7.27 & 27.96 & 12.21 & 15.11 & 15.68 & 14.41 \\
\hline
\end{tabular}

FN: Number of fertile nodes per plant. IN: Number of infertile nodes per plant. GN: grains number per plant. TGM: 1000-grain mass in grams. GY: grain yield in kilograms per hectare. CV: coefficient of variation. Means followed by the same letter in the column do not differ from each other at 0.05 probability by the Tukey's test. ns: non-significant.

The correlation between IPAR in the lower stratum and GY in the lower third was positive and significant $(\mathrm{r}=0.45)$, as was the correlation between IPAR in the lower stratum and the total plant GY $(r=0.46)$, while for the other variables, Pearson's correlation was not significant (Table 3$)$.

\section{Discussion}

The general response of soybean to intercepted radiation was that plants that intercepted more PAR inside of the canopy showed better performance in terms of fruiting. This response was modified over the phenophases, showing the absence of difference in IPAR among the cultivars at V6 and V9 stages. The last could be assigned to the similarity in LA distribution in late vegetative stages. At reproductive stages, plants differed in foliage density, and easily differed in IPAR. With the highest population density, 95R51 was the cultivar that intercepted the most radiation within the lower stratum along reproductive period, with the highest $k$ values at $\mathrm{V} 6, \mathrm{~V} 9$, and $\mathrm{R} 2$ stages. Among the studied soybean cultivars, the highest population densities resulted in a reduction of $k$ before and after flowering [24]. Such an outcome shows that 95R51 has morphological characteristics 
Table 2. One-thousand-grain mass and grain yield of four soybean cultivars with different architectural characteristics.

\begin{tabular}{ccc}
\hline Cultivars & TGM (g) & GY $\left(\mathrm{kg}^{\mathrm{h}} \mathrm{ha}^{-1}\right)$ \\
\hline BMX Ativa RR & $193 \mathrm{a}$ & $5242 \mathrm{~b}$ \\
NA 5909 RG & $165 \mathrm{~b}$ & $4924 \mathrm{c}$ \\
$95 \mathrm{R} 51$ & $196 \mathrm{a}$ & $5472 \mathrm{a}$ \\
BMX Potência RR & $141 \mathrm{c}$ & $4572 \mathrm{~d}$ \\
CV (\%) & 2.53 & 1.67 \\
\hline
\end{tabular}

TGM: one-thousand-grain mass in grams. GY: grain yield in kilograms per hectare. Means followed by the same letter in the column do not differ from each other at 0.05 level by the Tukey's test. CV: coefficient of variation.

Table 3. Pearson correlations between intercepted photosynthetically active radiation (IPAR) and grain yield (GY) of different soybean cultivars.

\begin{tabular}{ccccc}
\hline Variables & GY - LT & GY - MT & GY - UT & GY - T \\
\hline IPAR - Lower stratum & $0.45^{*}$ & 0.01 & 0.31 & $0.46^{*}$ \\
IPAR - Upper stratum & -0.002 & -0.17 & 0.08 & -0.08 \\
IPAR - Total & 0.22 & -0.16 & 0.24 & 0.15 \\
\hline
\end{tabular}

GY: grain yield in kilograms per hectare. LT: lower third of the plant canopy. MT: medium third of the plant canopy. UT: upper third of the plant canopy. T: total plant canopy. IPAR - intercepted photosynthetically active radiation. ${ }^{*}$ Significant at 0.05 level by the Tukey's test.

that facilitated light interception inside the canopy.

Given that soybean plants showed a high RIE, radiation was poorly distributed over the canopy profile. This became evident when IPAR was analyzed in a stratified manner by dividing canopy into lower and upper strata. In the upper stratum, the average IPAR were 90, 92, 89, and 92\% of total incident PAR for BMX Ativa RR, NA 5909 RG, 95R51, and BMX Potência RR, respectively. In other words, IPAR was 8 to 12 times higher in the upper than was in the lower canopy stratum. These results corroborate those reported by [24], which confirm that IPAR in the lower part of the canopy was $150 \%$ less than that in the upper stratum.

An uneven distribution of PAR in the canopy can mainly compromise diffuse radiation use by lower stratum leaves since the total incident radiation is limited to the upper stratum. This problem can be worsened by long cloudy and rainy periods, in which diffuse radiation contributes significantly to photosynthesis. In addition, a low IPAR in the lower stratum can compromise plant energy production and, consequently, limit crop yield. This damage becomes more pronounced since the lower stratum contributes around 35 and $45 \%$ of the total grain in a soybean plant [25].

The ability to intercept solar radiation by plants depends on $k$ value, which varies with leaf spatial structure, mainly leaf area index and leaf insertion angle 
[26]. This extinction coefficient reveals the degree of exponential reduction of solar radiation photons on the canopy, and this reduction infers in a low quality of PAR distribution [24]. Since $k$ value is the inverse of the LAI value [5], the highest values were observed at the soybean V6 stage. High $k$ was due to low LAI at this stage, however, with substantial capacity to intercept PAR. Contrarily, there was a reduction in $k$ at $\mathrm{V} 9$ stage since, at this period, LAI was practically doubled, and RIE was little altered. Thus, may be concluded that even though plants had an increased LA, their ability to intercept solar radiation was virtually equal to that at V6 stage. At R2 stage, the RIE for all cultivars was 0.99. This explains why $k$ values were higher for BMX Ativa RR and 95R51. Even though these cultivars presented a lower LA, they had the same RIE as the others.

The RIE value determines the proportion of the solar radiation reaching over the plant canopy is received by the plants [27], and is directly related to crop LAI since its increase results in enhanced IPAR [28]. At the R2 stage, the cultivars showed high LAI, high RIE values, and low radiation interception in the lower stratum. The increase in LAI may provide an increase in RIE, however, this interception occurs mainly in the upper stratum, increasing thus shadowing of the lower stratum [10].

An adjustment in the LAI of the cultivars is necessary to intercept $90 \%$ or more of the incident radiation. However, with less limitation of the photons flux from solar radiation to the lower stratum. In this study, a LAI between of 4 and 5 was the most appropriate for all cultivars, being reached at R4 stage. Soybean must attain LAI of 3.9 to be able to intercept $95 \%$ incident solar radiation [29]. However, it should not be generalized since this may vary among cultivars, crop management, phenological stage, and mainly plant leaf features.

In plant productive systems, IPAR becomes the most limiting factor for grain yield when other variables are already under control (diseases, pests, water availability, etc.). Light enrichment initiated at the early flowering, increased the seed yield from 144 to $252 \%$; while at the early podding, the increases were between 32 and $115 \%$ in grain yield [30]. This clearly shows that the light intercepted during and after the fruiting can be a factor in determining grain yield. BMX Potência RR had the longest cycle (121 days) and, consequently had the maximum levels of PAR accumulation between cultivars studied, but the lowest RUE. NA 5909 RG and 95R51 presented very similar RUE values, but 95R51 had the shortest cycle (102 days), which resulted in a lower accumulation of PAR.

A greater IPAR was achieved by 95R51 in the lower stratum at reproductive stages. For this reason, this cultivar showed higher effective fruiting in the lower third and, consequently, an improved productive performance. The number of reproductive structures in the early reproductive stages had no correspondence with the number found at physiological maturation. Although soybeans present a high grain yield potential, part of this potential is lost due to abscission of reproductive structures. These losses occur in function of the interaction with the environment and the competition between the plant organs by photoassimilates 
during the crop cycle [31]. Post-flowering stages are considered critical for grain yielding [32] since the availability of photoassimilates throughout this period affects crop productivity [33] [34]. In addition, other factors are involved in the abscission of reproductive structures in soybean cultivars, some of them are nutrients and endogenous concentration of some plant hormones [35].

The NA 5909 RG and BMX Potência RR cultivars had higher total number of nodes in the plant when compared to the other two cultivars used in the experiment. However, the larger number of nodes did not result in higher plant productivity. For this reason, the grains yield found in the lower third of these plants may be justified when considering the relationship between IN and FN.

NA 5909 RG attained equally high yield as BMX Ativa RR and 95R51 in the upper third, did not differ in the middle third, but showed less total productivity when compared to BMX Ativa RR and 95R51, due to NA 5909 RG low production in the lower third. This was related to lowlight interception associated with high abortion of the reproductive structures in upper strata. Therefore, interception of light in the lower stratum provides better source and sink relationship of the structures in that plant region, resulting in high productivity [36].

Expectedly, the IPAR in the upper stratum showed no correlation with grain yield since it was high for all the evaluated cultivars. On the other hand, the IPAR values were low in the lower stratum for all the cultivars. Therefore, the cultivars with higher IPAR values in the lower stratum (95R51 and BMX Ativa $\mathrm{RR}$ ) showed better performance regarding effective fruiting and IN/FN ratio. Given the above background, it may be reasoned that the soybean yield depends on IPAR levels and that part of this radiation should be intercepted in the lower plant stratum, as demonstrated by correlation analysis. These factors allow a greater production of photoassimilates, contributing to grain yield by means of a higher effective fruiting in the lower third. It may be concluded that developing a plant with high productivity in any environment would be unattainable. However, patterns of plants could be selected for a given environment in which the plant can express its productive potential, without being hampered by the low IPAR inside the canopy.

\section{Conclusion}

The soybean cultivars most efficient in the interception of photosynthetically active radiation inside the vegetative canopy have higher yields of grains due to a higher effective fruiting in the lower third.

\section{Acknowledgements}

The authors are grateful to Coordenação de Aperfeiçoamento de Pessoal de Nível Superior (CAPES) for financial support. PNPD/CAPES for scholarship of Andréia Caverzan and Prosup/CAPES for scholarship of Mariele Müller. Miroslava Rakocevic thanks the Consórcio Pesquisa Café for granted fellowship. 


\section{References}

[1] Nobel, P.S. (2005) Physicochemical and Environmental Plant Physiology. Elsevier/ Academic Press, San Diego.

[2] Monteith, J.L. and Moss, C.J. (1977) Climate and the Efficiency of Crop Production in Britain. Philosophical Transactions of Royal Society B, 281, 277-294. https://doi.org/10.1098/rstb.1977.0140

[3] Stockle, C.O. and Kemaniam, A.R. (2009) Crop Radiation Capture and Use Efficiency: A Framework for Crop Growth Analysis. In: Crop Physiology, Academic Press, San Diego, 145-170. https://doi.org/10.1016/B978-0-12-374431-9.00007-4

[4] Vos, J., Evers, J.B., Buck-Sorlin, G.H., Andrieu, B., Chelle, M. and Visser, P.H.B. (2010) Functional-Structural Plant Modelling: A New Versatile Tool in Crop Science. Journal of Experimental Botany, 61, 2101-2115. https://doi.org/10.1093/jxb/erp345

[5] Pilau, F.G. and Angelocci, L.R. (2015) Leaf Area and Solar Radiation Interception by Orange Tree Top. Bragantia, 74, 476-482. https://doi.org/10.1590/1678-4499.0130

[6] Liu, B., Li, Y.S., Liu, X.B., Wang, C., Jin, J. and Herbert, S.J. (2011) Lower Total Soluble Sugars in Vegetative Parts of Soybean Plants Are Responsible for Reduced Pod Number under Shading Conditions. Australian Journal of Crop Science, 5, 1852-1857.

[7] Lemoine, R., Camera, S.L., Atanassova, R., Dédaldéchamp, F., Allario, T., Pourtau, N., Bonnemain, J.L., Laloi, M., Coutos-Thévenor, P., Maurousset, L., Faucher, M., Girousse, C., Lemonnier, P., Parrilla, J. and Durand, M. (2013) Source-to-Sink Transport of Sugar and Regulation by Environmental Factors. Frontiers in Plant Science, 4, 272. https://doi.org/10.3389/fpls.2013.00272

[8] Larson, P. and Dickson, R. (1973) Distribution of Imported ${ }^{14} \mathrm{C}$ in Developing Leaves of Eastern Cottonwood According to Phyllotaxy. Planta, 111, 95-112. https://doi.org/10.1007/BF00386270

[9] Zuffo, A.M., Zambiazzi, E.V., Gesteira, G.S., Rezende, P.M., Bruzi, A.T., Soares, I.O. Gwinner, R. and Bianchi, M.C. (2015) Agronomic Performance of Soybean According to Stages of Development and Levels of Defoliation. African Journal of Agricultural Research, 10, 2089-2096. https://doi.org/10.5897/AJAR2014.9369

[10] Pengelly, B.C., Blamey, F.P.C. and Muchow, R.C. (1999) Radiation Interception and the Accumulation of Biomass and Nitrogen by Soybean and Three Tropical Annual Forage Legumes. Field Crops Research, 63, 99-112. https://doi.org/10.1016/S0378-4290(99)00029-5

[11] Behling, A., Sanquetta, C.R., Corte, A.P.D., Netto, S.P., Rodrigues, A.L., Caron, B.O. and Simon, A.A. (2016) Tracking Leaf Area Index and Coefficient of Light Extinction over the Harvesting Cycle of Black Wattle. Journal of Forestry Research, 27, 1211-1217. https://doi.org/10.1007/s11676-016-0279-1

[12] Procópio, S.O., Santos, J.B., Silva, A.A. and Costa, L.C. (2003) Leaf Development of Soybean and Bean Crops and Weeds. Ciência Rural, 33, 207-211. https://doi.org/10.1590/S0103-84782003000200005

[13] Portes, T.A. and Melo, H.C. (2014) Light Interception, Leaf Area and Biomass Production as a Function of the Density of Maize Plants Analyzed using Mathematical Models. Acta Scientiarum Agronomy, 36, 457-463. https://doi.org/10.4025/actasciagron.v36i4.17892

[14] Brouwer, B., Ziolkowska, A., Bagard, M., Keech, O. and Gardeström, P. (2012) The Impact of Light Intensity on Shade-Induced Leaf Senescence. Plant, Cell \& Environment, 35, 1084-1098. https://doi.org/10.1111/j.1365-3040.2011.02474.x 
[15] Peel, M.C., Finlayson, B.L. and McMahon, T.A. (2007) Updated World Map of the Koppen-Geiger Climate Classification. Hydrology Earth System Sciences, 11, 1633-1644. https://doi.org/10.5194/hess-11-1633-2007

[16] Santos, H.G., Jacomine, P.K.T., Anjos, L.H.C., Oliveira, V.A., Oliveira, J.B., Coelho, M.R., Lumbreras, J.F. and Cunha, T.J.F. (2006) Sistema brasileiro de classificação de solos. [Brazilian System of Soil Classification.] Embrapa Solos, Rio de Janeiro.

[17] De Oliveira, A.C.B. and da Rosa, A.P.S.A. (2014) Indicações Técnicas para a cultura da soja no Rio Grande do Sul e em Santa Catarina, safras 2014/2015 e 2015/2016. [Technical Indications for Soybean Culture in Rio Grande do Sul and Santa Catarina, 2014/2015 and 2015/2016 Crops.] Embrapa Clima Temperado, Pelotas.

[18] Fehr, W.R. and Caviness, C.E. (1977) Stages of Soybean Development. Iowa State University of Science and Technology, Ames, Special Report, 80, 12 p.

[19] Monsi, M. and Saeki, T. (2005) On the Factor Light in Plant Communities and Its Importance for Matter Production. Annals of Botany, 95, 549-567. https://doi.org/10.1093/aob/mci052

[20] Hirose, T. (2005) Development of the Monsi-Saeki Theory on Canopy Structure and Function. Annals of Botany, 95, 483-494. https://doi.org/10.1093/aob/mci047

[21] Sinclair, T.R. and Muchow, R.C. (1999) Radiation Use Efficiency. Advances in Agronomy, 65, 215-265.

[22] Casaroli, D., Fagan, E.B., Simon, J., Medeiros, S.P., Paulo Augusto Manfron, P.A., Neto, D., Lier, Q.J.V., Müller, L. and Martin, T.N. (2007) Radiação solar e aspectos fisiológicos na cultura de soja uma revisão. [Solar Radiation and Physiologics Aspects in Soybean-A Review.] Revista da FZVA, 14, 102-120.

[23] Thimijan, R.W. and Heins, R.D. (1983) Photometric, Radiometric, and Quantum Light Units of Measure: A Review of Procedures for Interconversion. Hortscience, 18, 818-822.

[24] Petter, F.A., Silva, J.A., Zuffo, A.M., Andrade, F.R., Pacheco, L.P. and Almeida, F.A. (2016) Does High Seeding Density Increase Soybean Productivity? Photosynthetically Active Radiation Responses. Bragantia, 75, 173-183. https://doi.org/10.1590/1678-4499.447

[25] Bahry, C.A., Nandino, M., Venske, E., Fin, S.S., Zimmer, P.D., Souza, V.Q. and Caron, B.O. (2014) Effect of Additional Nitrogen on Soybean Yield Components in Water Stress Condition. Revista Ceres, 61, 155-160.

[26] Ruiz, R.A. and Bertero, H.D. (2008) Light Interception and Radiation Use Efficiency in Temperate Quinoa (Chenopodium quinoa Willd.) Cultivars. European Journal of Agronomy, 29, 144-152.

[27] Pilau, F.G. and Angelocci, L.R. (2016) Assessing the Coffee Canopy Light Absortion Based on the Leaf Area. Coffee Science, 11, 127-136.

[28] Müller, A.G. and Bergamaschi, H. (2005) Eficiências de interceptação, absorção e uso da radiação fotossinteticamente ativa pelo milho (Zea mays L.), em diferentes disponibilidades hídricas e verificação do modelo energético de estimativa da massa seca acumulada. [Efficiency of Interception, Absorption, and Photossintetically Active Radiation Use in Maize Crops (Zea mays L.) Submitted to Different Water Conditions and Dry Mather Estimation by Energetic Model.] Revista Brasileira de Agrometeorologia, 13, 27-33.

[29] Schöffel, E.R. and Volpe, C.A. (2001) Efficiency in Conversion of Photosynthetically Active Radiation Intercepted by Soybean to Biomass Production. Revista Brasileira de Agrometeorologia, 9, 241-249. 
[30] Mathew, J.P., Herbert, S.J., Zhang, S.H., Rautenkranz, F.A.A. and Litchfield, G.V. (2000) Differential Response of Soybean Yield Components to the Timing of Light Enrichment. Agronomy Journal, 92, 1156-1161. https://doi.org/10.2134/agronj2000.9261156x

[31] Navarro, H.M. and Costa, A.C. (2002) Contribuição relativa dos componentes do crescimento para produção de grãos de soja. [Relative Contribution of Yield Componentes for Grain Production in Soybean.] Pesquisa Agropecuária Brasileira, 37, 269-274. https://doi.org/10.1590/S0100-204X2002000300006

[32] Egli, D.B. (1998) Seed Biology and the Yield of Grain Crops. CAB International, Madison.

[33] Bruin, J.L. and Pedersen, P. (2009) Growth, Yield, and Yield Component Changes among Old and New Soybean Cultivars. Agronomy Journal, 101, 124-130. https://doi.org/10.2134/agronj2008.0187

[34] Jiang, H. and Egli, D.B. (1995) Soybean Seed Number and Crop Growth Rate during Flowering. Agronomy Journal, 87, 264-267. https://doi.org/10.2134/agronj1995.00021962008700020020x

[35] Nonokawa, K., Kokubun, M., Nakajima, T., Nakamura, T. and Yoshida, R. (2007) Roles of Auxin and Cytokinin in Soybean Pod Setting. Plant Production Science, 10, 199-206. https://doi.org/10.1626/pps.10.199

[36] Liu, B., Liu X.B., Wang, C., Li, Y.S., Jin, J. and Herbert, S.J. (2010) Soybean Yield and Yield Component Distribution across the Main Axis in Response to Light Enrichment and Shading under Different Densities. Plant Soil Environment, 56, 384-392. 